\begin{tabular}{|c|c|}
\hline ב & $\begin{array}{c}\text { International Journal of Current Research } \\
\text { and Academic Review }\end{array}$ \\
\hline 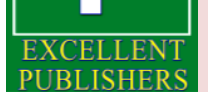 & $\begin{array}{c}\text { ISSN: 2347-3215 (Online) :,; Volume } 5:, ; \text { Number } 10 \text { (October-2017) } \\
\text { Journal homepage: http://www.ijcrar.com }\end{array}$ \\
\hline
\end{tabular}

doi: https://doi.org/10.20546/ijcrar.2017.510.007

\title{
Impact of Immobilization Techniques of Brewing Strain Saccharomyces carlsbergensis on Fermentation Kinetics
}

\author{
Luljeta Pinguli*, Ilirjan Malollari, Rozana Troja, Vilma Gurazi and Terkida Vaso \\ Department of Industrial Chemistry, Faculty of Natural Sciences, University of Tirana, Albania \\ *Corresponding author
}

\section{Abstract}

The aim of our study was to study impact of immobilization technique on fermentation performance based on a comparative analysis of different mathematical structures known by far for modeling of batch alcoholic fermentation with free and immobilized cells of Saccharomyces carlsbergensis using real experimental data. Our study was focused on comparing three different immobilized brewing yeast fermentations with traditional free cell fermentation in experimental scale. The immobilization techniques used were: entrapment and capsulation method in alginate and gel immobilization in gelatin support. Fermentation performances were analyzed based on fermentation rate parameters, kinetic models and yeast cell physiology. Conclusions were drawn about the influence of cell immobilization on the batch process. Entrapment immobilized yeast fermentation was the closer one to the free cell fermentation. Due to the high diffusion inside the biocatalyst particles, inhibitory phenomena were avoided and the microbial activity was preserved. The vitality of the yeast cells, specific growth rate and the sugar uptake rate were directly related to the medium conditions and permeability of the immobilized capsule. Also immobilization based to kinetic parameters decrease the substrate and product inhibition phenomena compared to free yeast fermentation.
\end{abstract}

\section{Article Info}

Accepted: 04 September 2017

Available Online: 20 October 2017

\author{
Keywords \\ Yeast immobilization, \\ Entrapment, \\ Capsulation, \\ Fermentation, \\ Kinetic parameters, \\ Modeling.
}

\section{Introduction}

Yeast immobilization techniques are used to improve fermentation performance through physico-chemical fixation of cells in different solid matrix, protecting the cell from the surrounding medium. Choosing the right immobilization technique is very important, in order to protect cell activity, without changing the morphology and physiology of the cells (Kourkoutas et al., 2004; Gorecka and Jastrzebska, 2011). The aim of this study is to choose the most suitable immobilization technique that protects the yeast cells providing a good fermentation performance compared to free yeast cell fermentation. For the heterogeneous systems, not only the value of the biochemical reaction rate is affected, but also the kinetic model is modified compared to the ideal models describing the substrate consumption or product formation. For these reasons, the kinetic parameters of the biochemical reactions with immobilized cells differ from those of homogeneous environments.

In order to control inhibition caused by high concentrations of substrate and product as well as to enhance yield, cell immobilization approaches have been applied in ethanol production. The advantages of immobilized cell over free cell systems have been 
extensively reported. Immobilized cell fermentation has been shown to be more effective than the free yeast process, mainly due to the enhanced fermentation productivity, feasibility for continuous processing, cell stability and lower costs of recovery and recycling and downstream processing. However, immobilized cells still have limited industrial application. The process of immobilization changes not only the environment, but also the physiological and morphological characteristic of cells, and the catalytic activity of enzymes. Therefore the fermentation conditions (kinetics) of the free yeast fermentation and of the immobilized cell process are different (Georgi Kostov et al., 2012).

Modeling batch fermentation process by the yeast Saccharomyces carlsbergensis immobilized in Naalginate gel beds were considered. Well known mathematical models were used for simulation investigations. Kinetic of glucose consumption, ethanol production and effect of substrate and product inhibition, were study based on batch fermentations performance. However there is no model universal structure that could perfectly suit glucose fermentation by all possible kinds of strains since each particular strain has its specifics that require an individual approach to kinetics modeling (Duarte, J. C et al., 2013; Snoep, J.L et al., 1999).

\section{Materials and Methods}

\section{Cell immobilization}

There were used three different immobilization techniques that require yeast cells to be incorporated in a semi-permeable matrix. These techniques are based on incorporating the cells in a porous, semi-permeable matrix, which prevents cells from diffusing into the surrounding medium allowing the mass transfer of nutrients and metabolites. Were used three different bead sizes $(4 \mathrm{~mm}, 5.3 \mathrm{~mm}$ and $7 \mathrm{~mm})$ and three different immobilization techniques:

Capsulation immobilization [Fig. 1(a)]

Entrapment Immobilization [Fig. 2(b)]

Gel immobilization [Fig. 3(c)]

Capsulation Immobilization: A 1,3\% calcium chloride $\mathrm{CaCl}_{2}$ and $1,3 \%$ of carboxymethylcellulose solution and a $0.6 \%$ solution of sodium alginate (Figure 1A) was prepared (Canaple, 2002; Rrathone et al., 2013).

Entrapment Immobilization: Yeast cells were mixed with the Na-alginate $6 \%$ and poured drop by drop in the calcium chloride solution $0.1 \mathrm{M}$ and left for 30 minutes in order to increase their stability (Figure 1B), (Duarte et al., 2013 and http://www.fao.org/docrep/w7241e/ w7241e0a.htm).

Gelatin Immobilization: A $10 \%$ solution of gelatin was prepared and mixed with yeast cell suspension, providing a solid structure for the yeast. A $20 \%$ formaldehyde solution was added to increase the stability of the gel prepared. Once the stability was increased, the gel was stored in fridge in $4^{\circ} \mathrm{C}$ for $30 \mathrm{~min}$ (Figure 1C), (Lee, 2008; Nam Sun Wang, 1988).

Batch fermentation was carried out in $250 \mathrm{ml}$ volume flasks, in three different fermentation environments. As fermentation medium was used beer wort in $12^{0}$ Plato, $16^{\circ}$ Plato and $12^{\circ}$ Plato $+5 \%$ alcohol. Cell density used in the medium $1 \mathrm{~g} / \mathrm{l}$ and $2 \mathrm{~g} / \mathrm{l}$.

\section{Mathematical models}

We chose simplified mass balance mathematical models that reflect only the kinetic rates of the main process reactions: biomass growth, ethanol production and substrate consumption for biomass and product formation (Aiba et al., 2000). The fermentation process kinetics was described with the ordinary differential equation (Di Serio et al., 2001):

$$
\begin{aligned}
& \frac{d X}{d t}=\mu X \\
& \frac{d P}{d t}=q X \\
& \frac{d S}{d t}=-\frac{1}{Y_{X / S}} \frac{d X}{d t}=-\frac{1}{Y_{P / S}} \frac{d P}{d t}
\end{aligned}
$$

Where $\mathrm{X}$ was biomass concentration, $\mathrm{P}$ is ethanol concentration, $S$ substrate concentration, $\mathrm{Y}_{\mathrm{X} / \mathrm{S}}$ and $\mathrm{Y}_{\mathrm{P} / \mathrm{S}}$ were yield coefficients, $\mu$ and $q$ were specific growth and product accumulation rates (Panikov, 1995).

The main kinetic parameters are:

Maximal specific growth rate $\mu_{\max }$,

Monod constant, $K_{s}$ value is the concentration of substrate when $\mu$ is equivalent to half of $\mu_{\max }$

The inhibitor constant, $\mathrm{K}_{\mathrm{i}}$ is an indication of how potent an inhibitor is, it is the concentration required to produce half maximum inhibition. 
In this research following models are used:

Monod $\mu=\mu_{\max } \frac{s}{s+K_{s}}$

Contois $\mu=\mu_{\max } \frac{s}{K_{S} \times x+s}$

Teisser $\mu=\mu_{\max }\left(1-e^{-S / K_{S}}\right)$

Substrate inhibition $\mu=\mu_{\max } \frac{s}{K_{S}+s} e^{-S / K_{I}}$

Product inhibition

$\mu=\mu_{\max } \frac{s}{s+K_{s}} \exp \left(-K_{i}^{*} p\right)$

\section{Results and Discussion}

\section{Kinetic parameters}

To evaluate fermentation performance based on kinetic constant $\mu_{\max }$ and $\mathrm{Ks}$, we have used three linearization methods:

Lineweaver - Burk $\frac{1}{\mu}=\frac{K_{s}}{\mu_{\max }} \frac{1}{s}+\frac{1}{\mu_{\max }}$

Hans Woolf $\frac{s}{\mu}=\frac{1}{\mu_{\max }} s+\frac{K_{s}}{\mu_{\max }}$

Eadie Hofslee $\mu=-K_{s} \frac{\mu}{s}+\mu_{\max }$

The highest correlation coefficient was chosen, and $\mathrm{K}_{\mathrm{i}}$ was determined by the mathematical method trial and error.

The maximum specific growth rate for entrapment yeast cells is almost the same compared to free yeast cell as high is the cell yeast density used in normal fermentation medium and smaller the bead size is. During fermentation, the diameter of immobilized beads increased and structure released more cells in the medium. In the present investigation, they were used in a very good yeast condition, up to six batches. Entrapment and capsulated immobilization techniques protected the morphology of cells, and supported cells growth and budding (Fig. 5). Gelatin immobilization techniques would be unrecommendable as cell growth is not supported.

Results of gel immobilization showed that the immobilization support is unstable and dissolves into the fermentation medium. Consequently, the immobilization technique did not have any impact on the fermentation process. Neither the entrapment method, nor the capsulation immobilization method showed differences between fermentation processes. However, there were differences compared to free yeast cell fermentation rate.

\section{Morphological characteristics of yeast cells in immobilized beads}

Inappropriateness of the gelatin immobilization technique is clearly depicted in the Figure 5B. No sign of budding phase was shown and cell growth stopped. In addition, contamination rate was very high. Compared to entrapment and capsulated immobilized yeast, cell growth could be noted (Figure 5A/5C). Cells were very good developed and multilateral or unilateral budding and pseudomycelium formation was shown. Cell counting performed by Thomas camera showed that cell vitality increases after fermentation in immobilized beads, compared to free cell suspension.

Further investigation was done for immobilized yeast with entrapment method as the most similar one with traditional free yeast cell fermentation. Were used three different bead size and also different cell density in the medium.

The system differential equations (1) is a classic description of various biotechnological processes. We tested 12 mathematical models obtained by different authors and applied for different biotechnological processes. The careful analysis of that work and our experimental results restricted our choise to 5 of these 12 mathematical models. For some of the discarded models unsual and unexplained constant values, even from a biological point of view, were obtained, while in other models it was impossible to identify the parameters. The mathematical models chosen as a result of the preselection are listed: equation (2a) - (2e). The obtained kinetic parameters for all the investigated models are given in Table 1 and 2 . 
Fermentation model simulation based on evaluated kinetic parameters

Figure 6 shows the model simulation result comparison with experimental data for the specific growth rate modeling equation. As seen, all the identified models describe with relatively good accuracy the batch fermentation process in the both cases (with and without cell immobilization). In order to choose the best model, it is important to consider how well it fit experimental data with Monod model.

Looking at Figure 6(b), we can conclude that in the case of free cell fermentation the model of Teisser do not fit in comparison to the rest of the rest of the models. In the case of the free cell fermentation, we have high values of the parameters $\mathrm{K}_{\mathrm{s}}$ and $\mathrm{Y}_{\mathrm{X} / \mathrm{s}}$. In low cell density Monod and Contois model fit well with experimental data, whereas in high cell density experimental data do not fit with any models.

A similar analysis can be done for the models of the second case of immobilized cell fermentation, Figure 6a. Since immobilized cells growth inside beads pearls, they are restricted by diffusion resistances and have a lower maximum specific growth rate. The decreasing of the specific growth rate is due to the internal diffusion resistances rather than due to the external ones because the process is carried out with intensive stirring and hence the main resistance is due to the substrate diffusion through the alginate pores. In that case the models have lower value of $\mathrm{K}_{\mathrm{s}}$ in comparison with those for the free cell fermentation. This could be explained with higher concentration of viable yeasts cells in the bioreactor working volume.

In Figure 7 are given comparison of the mathematical models, in case of substrate inhibition. Figure 7(a), shows cell immobilized $(4 \mathrm{~mm})$ and we see that Monod, Contois and Teisser models do not fit at all with experimental data. From the results obtained fit the equation (2d), which has an exponential dependence. In this case we have the impact of the inhibition constant $\mathrm{K}_{\mathrm{i}}$, that reduces the maximum specific growth rate and increases the semi saturation constant $\mathrm{K}_{\mathrm{s}}$. In the Figure 7(b), performance is shown for the free cell fermentation and it also has an exponential dependence, due to the substrate inhibition maximum specific growth rate decrease more and the semi saturation constant $\mathrm{K}_{\mathrm{s}}$ and inhibition constant $\mathrm{K}_{\mathrm{i}}$ increase even more.

In Figure 8, are given comparison of the mathematical models, in case of product inhibition. Figure 8(a), shows cell immobilized $(4 \mathrm{~mm})$ and Monod, Contois and Teisser models are far from experimental data during the exponential cell growth. From the results the model fit the equation (2e), which has an exponential dependence.

The values of $K_{1}$ parameter are very low. This is because the obtained ethanol concentration is much lower than the concentration that causes complete cell growth inhibition for our experimental data. In the Figure 8(b), is represented free cell yeast fermentation performance which is exponential too.

Table.1 Kinetic constants $\mu_{\max }$ and Ks for immobilized yeast with entrapment and capsulation method compared to free cell fermentation

\begin{tabular}{|c|c|c|c|c|}
\hline & & Free cell & Entrapment (4mm) & Capsulation (4mm) \\
\hline \multirow[t]{2}{*}{$12^{0}$ Plato fermentation } & $\mathrm{K}_{\mathrm{S}}\left({ }^{0} \mathrm{P}\right)$ & 10.2 & 7.1 & 14.3 \\
\hline & $\mu_{\operatorname{MAX}}(1 / h)$ & 0.48 & 0.4 & 0.11 \\
\hline \multirow[t]{2}{*}{$16^{0}$ Plato fermentation } & $\mathrm{K}_{\mathrm{S}}\left({ }^{0} \mathrm{P}\right)$ & 22.4 & 7.1 & 26.2 \\
\hline & $\mu_{\operatorname{MAX}}(1 / h)$ & 0.38 & 0.471 & 0.18 \\
\hline \multirow[t]{2}{*}{$20^{0}$ Plato fermentation } & $\mathrm{K}_{\mathrm{S}}\left({ }^{0} \mathrm{P}\right)$ & 24 & 21.4 & 23.1 \\
\hline & $\mu_{\operatorname{MAX}}(1 / h)$ & 0.22 & 0.32 & 0.26 \\
\hline \multirow{2}{*}{$\begin{array}{c}12^{0} \text { Plato }+5 \% \text { alcohol } \\
\text { fermentation }\end{array}$} & $\mathrm{K}_{\mathrm{S}}\left({ }^{0} \mathrm{P}\right)$ & 18 & 15.6 & 16.1 \\
\hline & $\mu_{\text {MAX }}(1 / h)$ & 0.11 & 0.135 & 0.128 \\
\hline \multirow{2}{*}{$\begin{array}{c}12^{0} \text { Plato }+20 \% \text { alcohol } \\
\text { fermentation }\end{array}$} & $\mathrm{K}_{\mathrm{S}}\left({ }^{0} \mathrm{P}\right)$ & 12.3 & 13.4 & 13.2 \\
\hline & $\mu_{\operatorname{MAX}}(1 / \mathrm{h})$ & 0.0008 & 0.01 & 0.11 \\
\hline
\end{tabular}


Table.2 Identified model parameters for immobilized entrapment yeast $(1 \mathrm{~g} / \mathrm{l})$, for three different bead diameter in inhibitory and non-inhibitory conditions

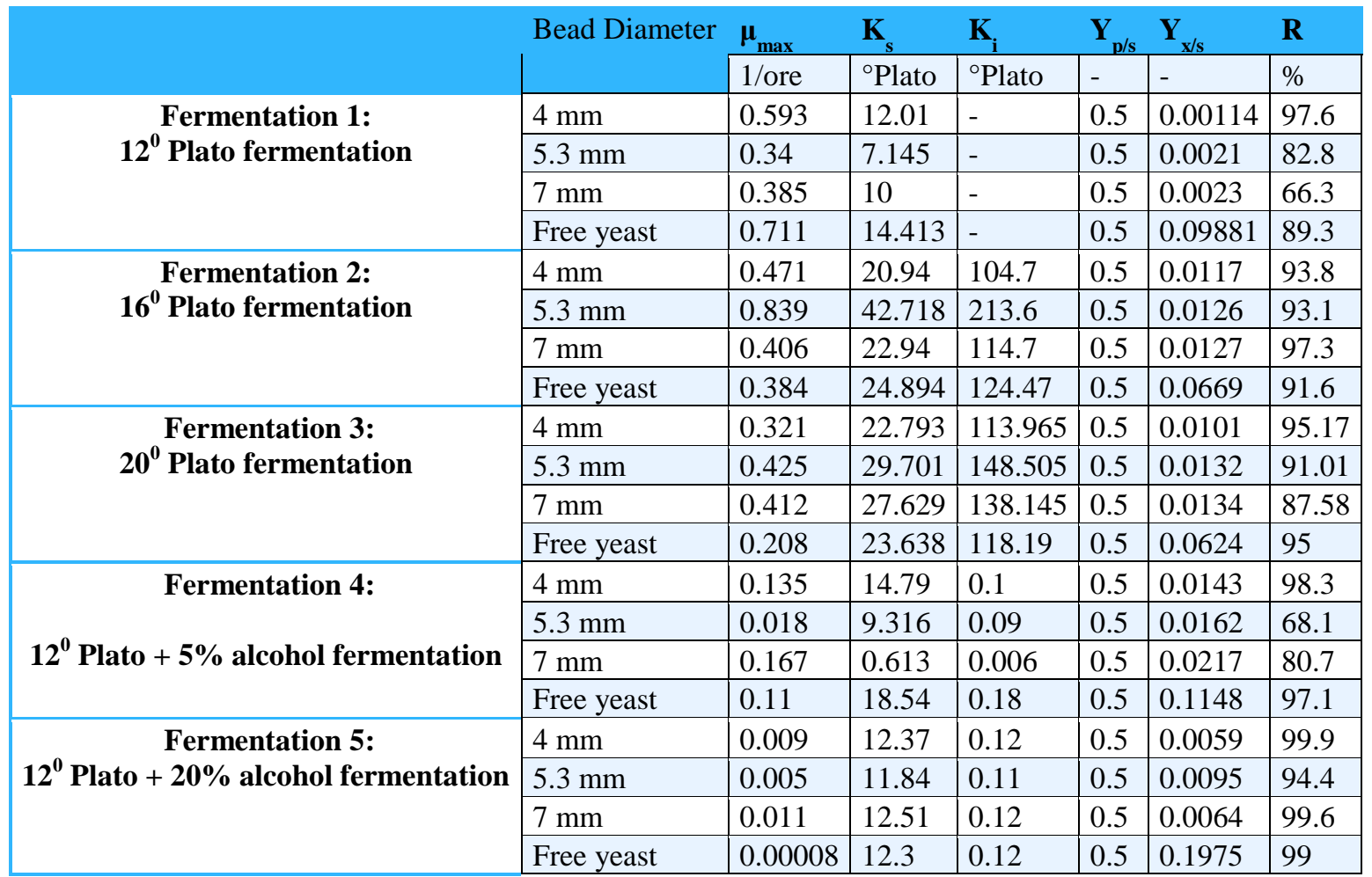

Fig.1 Immobilized yeast: a-capsulation immobilization, b- entrapment immobilization, c- gelatine immobilization
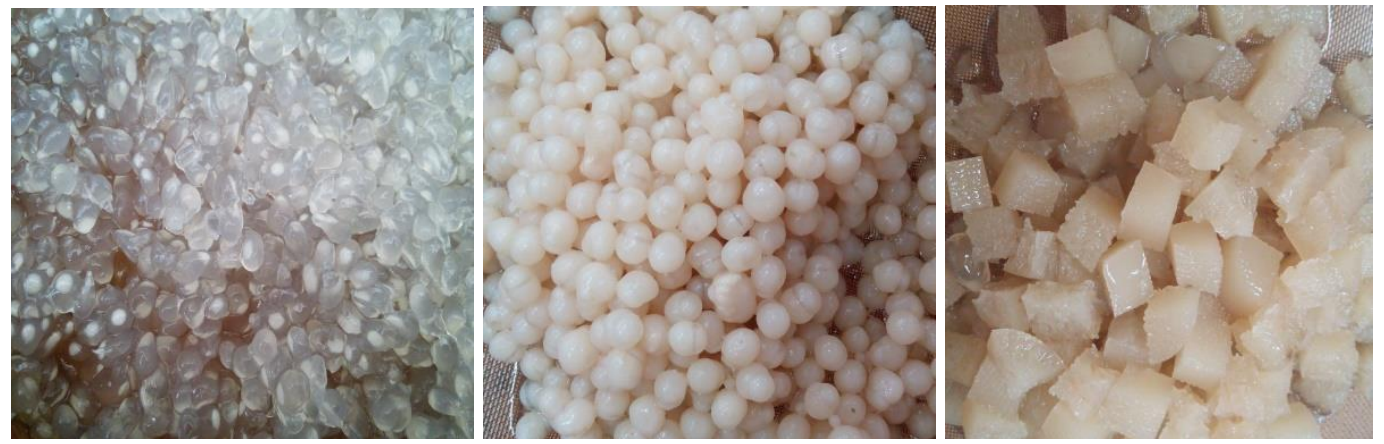

Fig.2 Example of linearization methods used for constant determinations

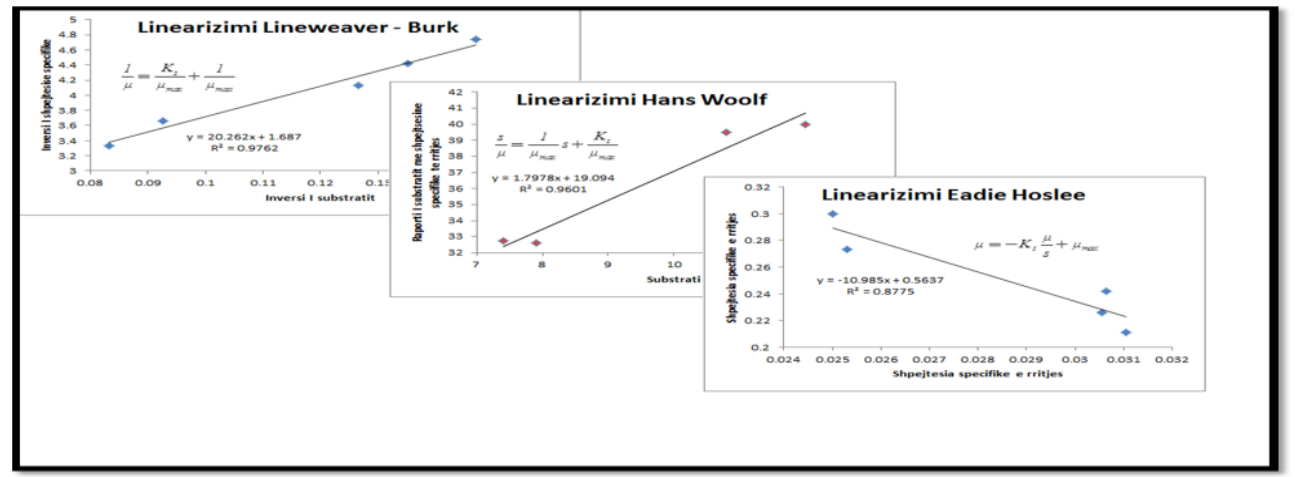


Fig.3 Comparison of maximum specific growth rate $\left(\mu_{\max }\right)$ for free cell fermentation, entrapment and capsulation immobilization fermentation in different medium conditions

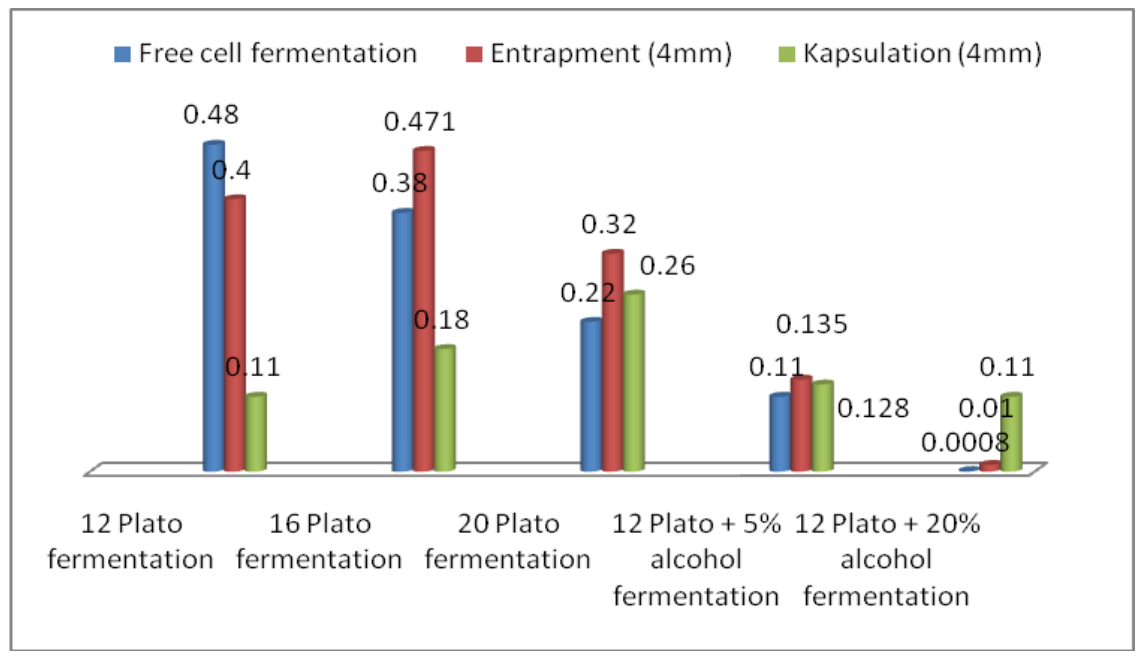

Fig.4 Comparison of half saturation constant for free cell fermentation, entrapment and capsulation immobilization fermentation in different medium conditions

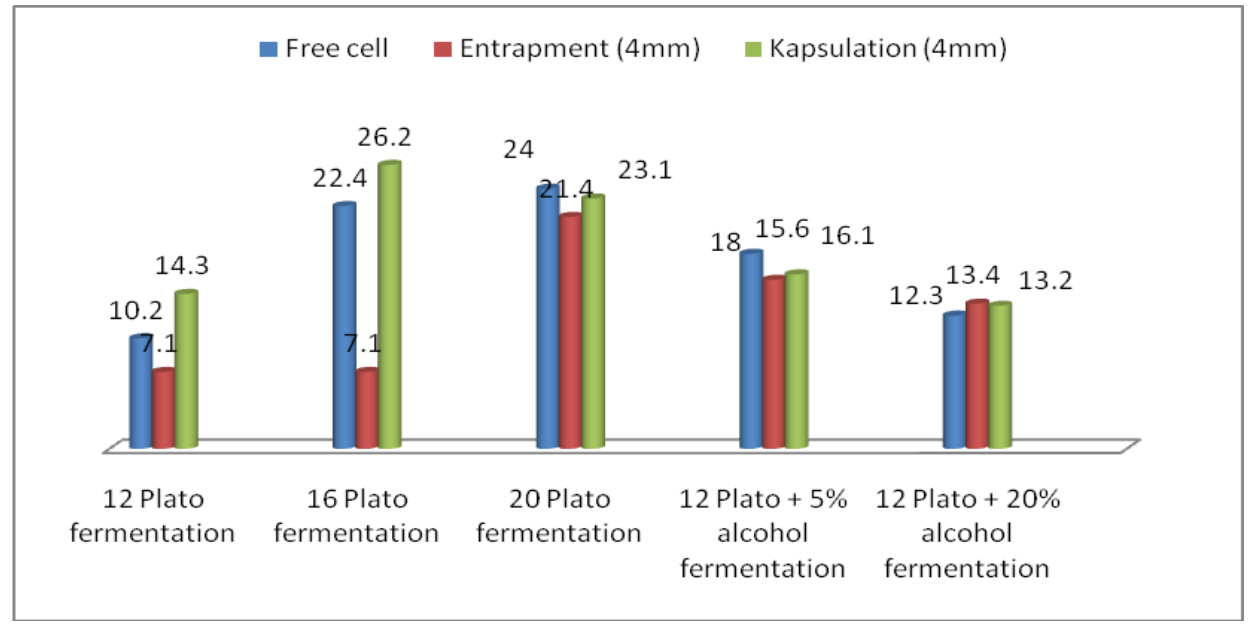

Fig.5 Microscopy images for immobilized yeast cells

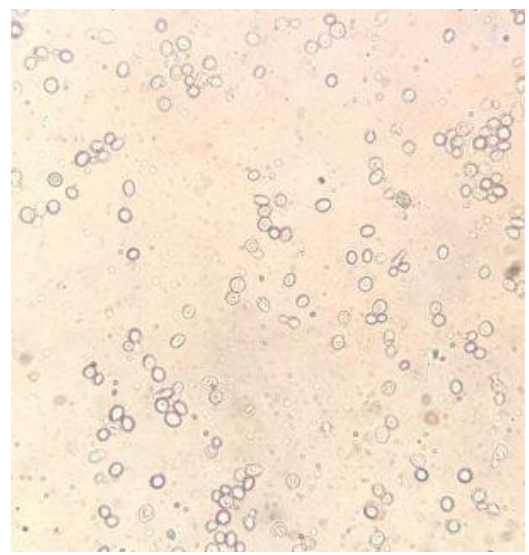

A (entrapment)

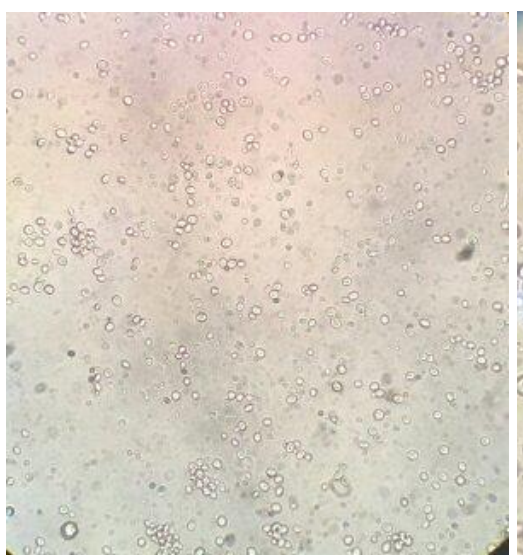

B (gel support)

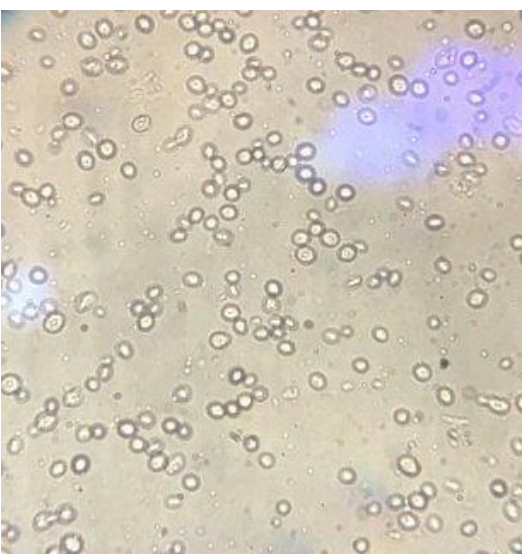

C (capsulation) 
Fig.6 Comparison of mathematical models for specific growth rate in the cases of immobilized cell (4mm) (a) and free cells (b), in $12^{0}$ Plato fermentation

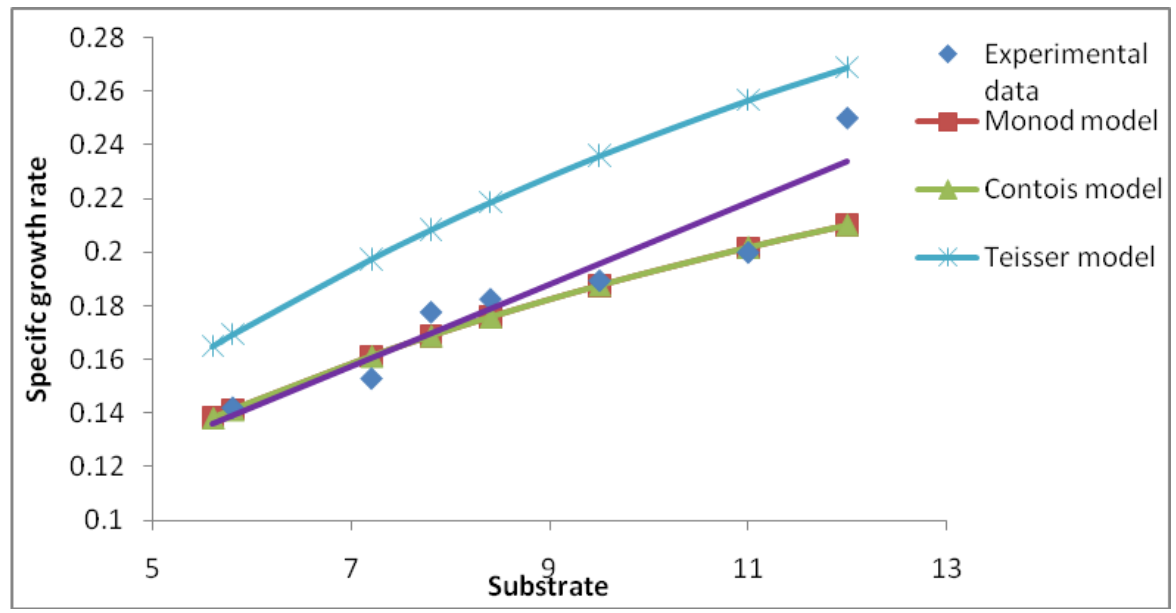

(a)

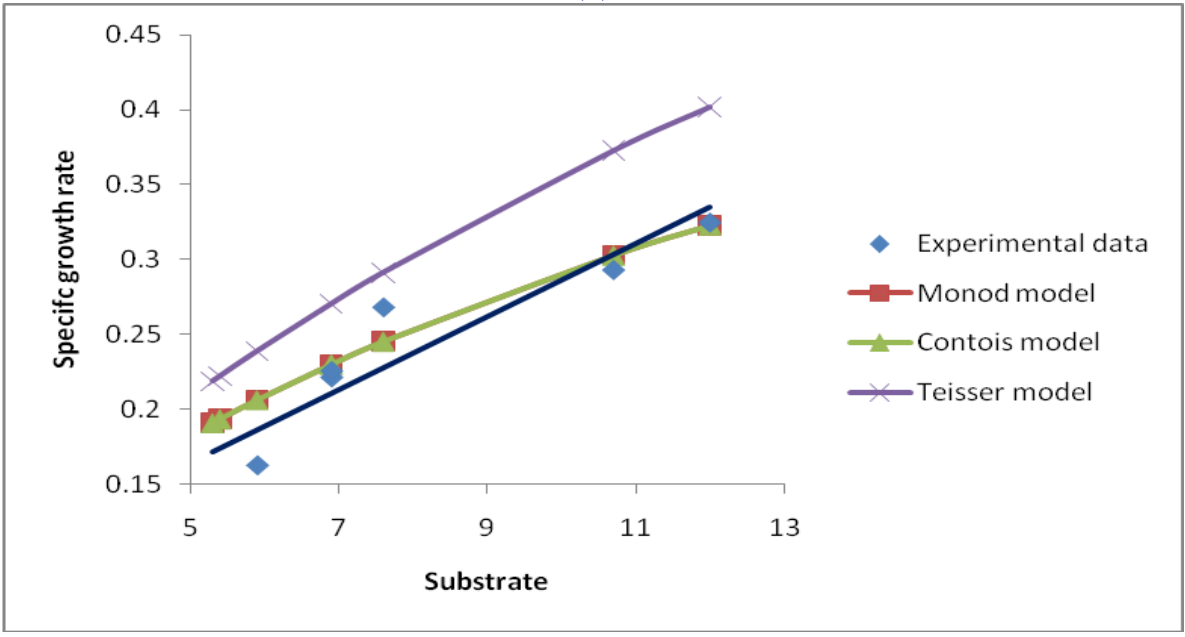

(b)

Fig.7 Comparison of mathematical models for specific growth rate in the cases of immobilized cell (4mm) (a) and free cells (b), in the second fermentation

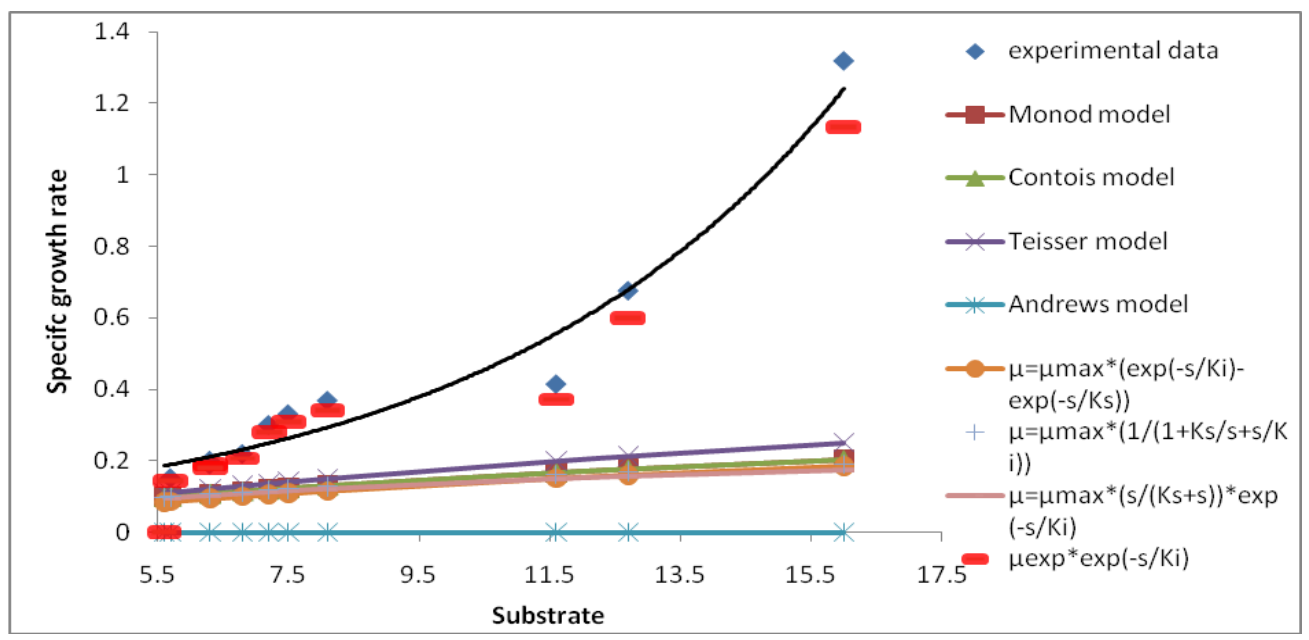

(a) 


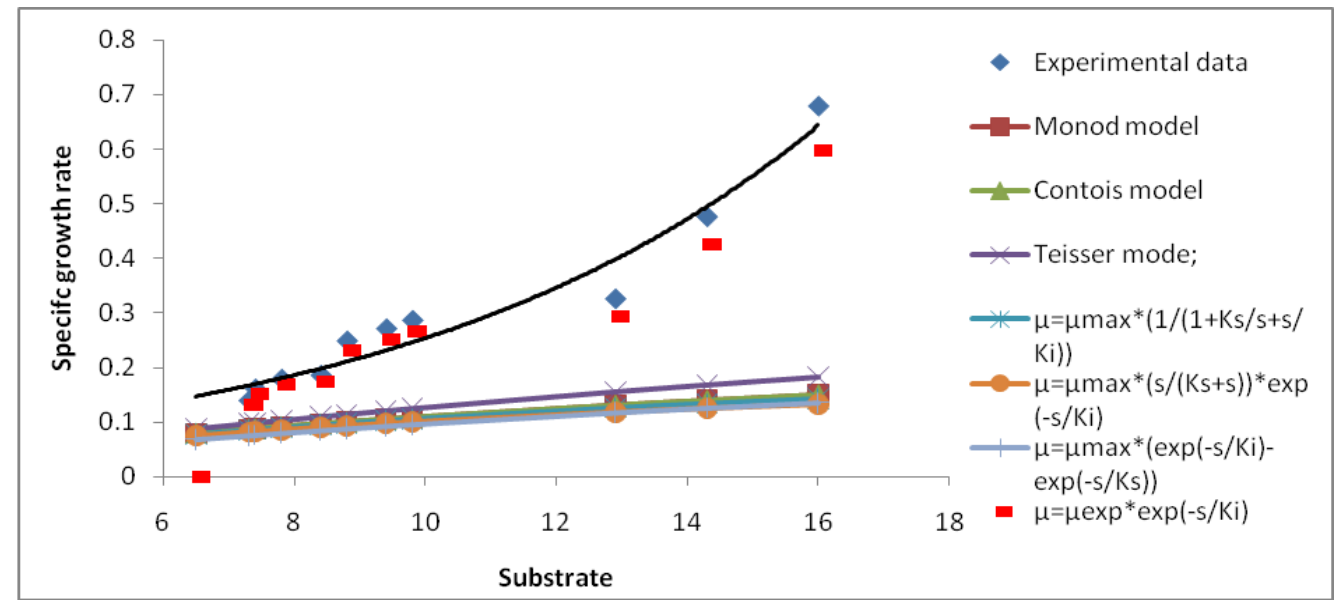

(b)

Fig.8 Comparison of mathematical models for specific growth rate in the cases of immobilized cell (4mm) (a) and free cells (b), in the fourth fermentation

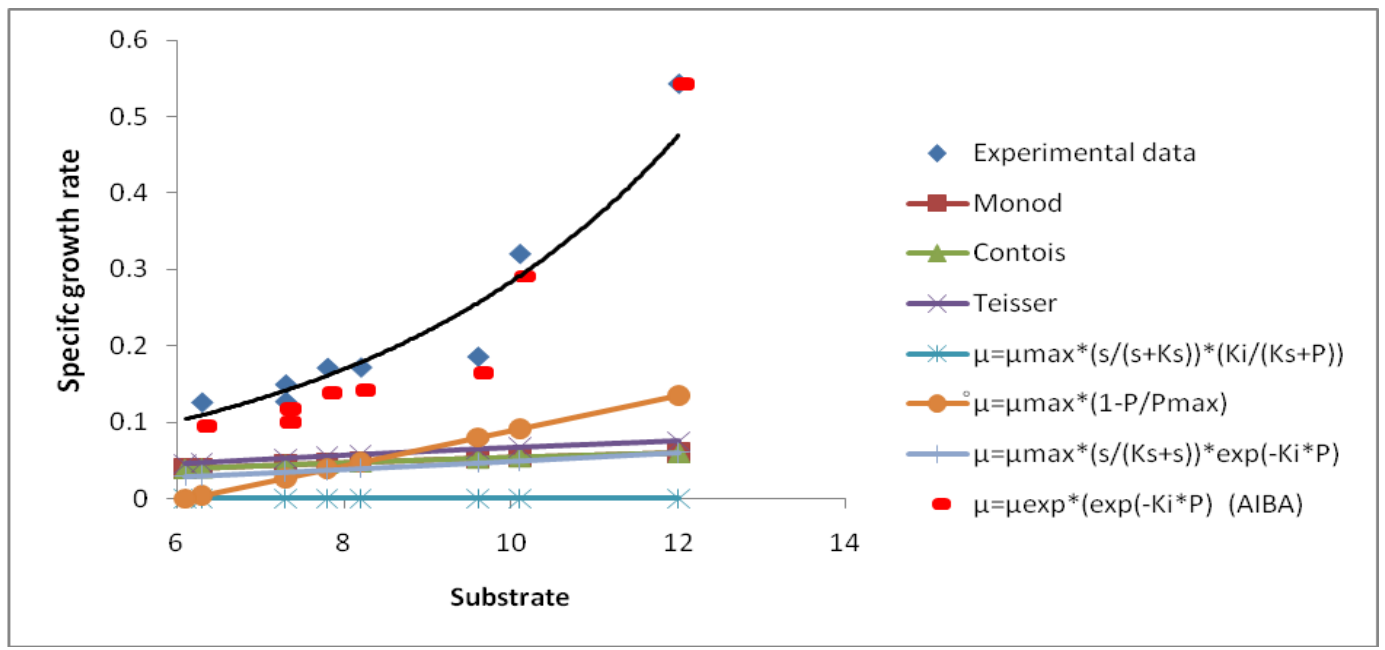

(a)

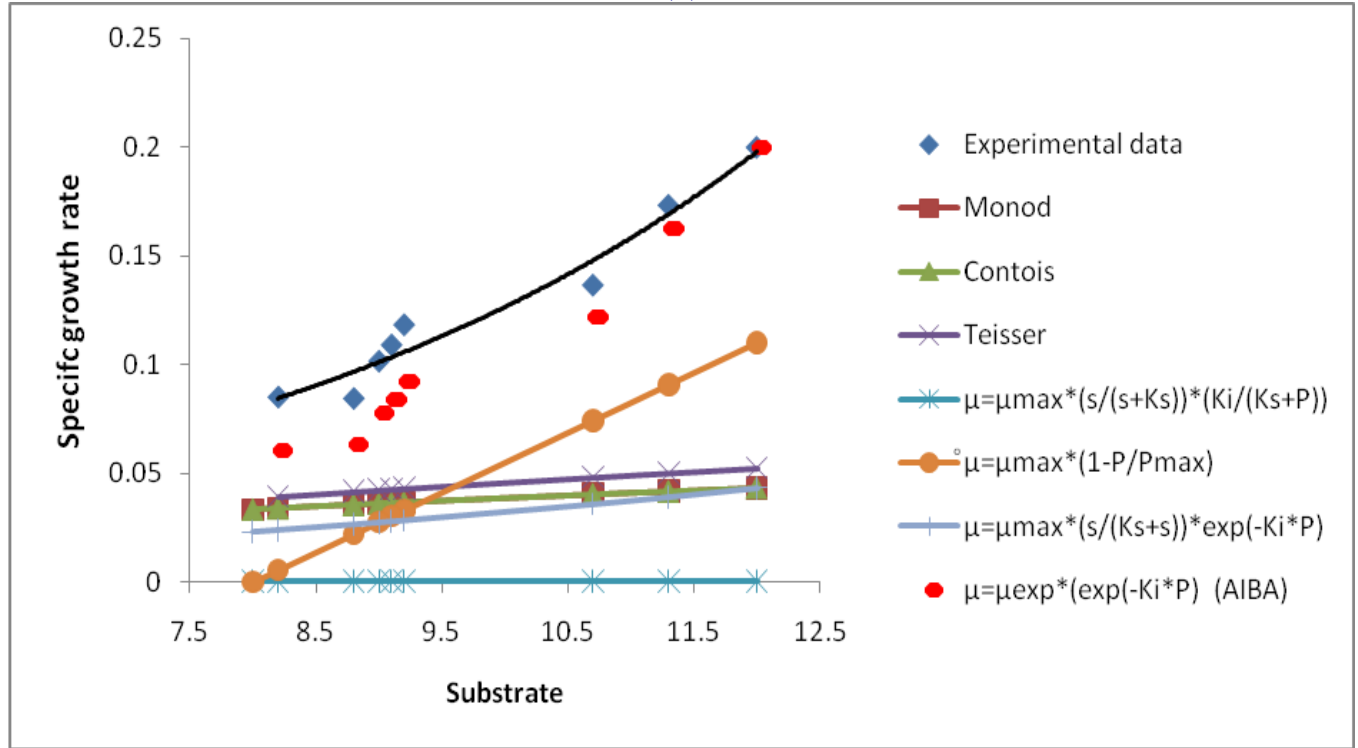

(b) 
Fig.9 Constant comparison for inhibitory and non-inhibitory conditions for different cell density in the medium

(Entrapment immobilized method, $4 \mathrm{~mm}$ bead size)

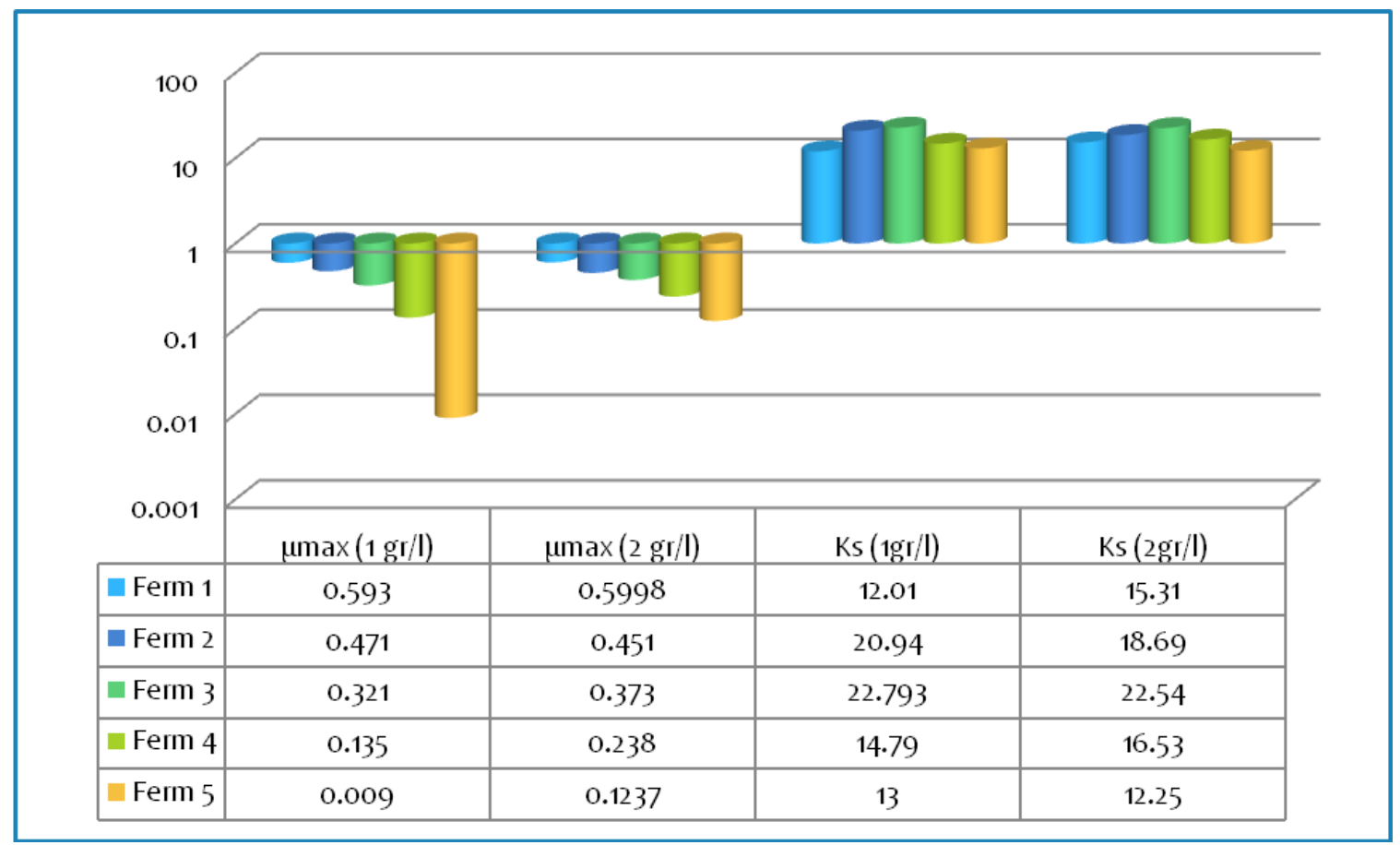

From Figure 9, based on kinetic parameter analyses it is very clear that substrate and product inhibition decrease significantly $\mu_{\max }$. This effect is stronger for product inhibition compared to substrate inhibition. The opposite is for half saturation constant. Increasing cell density in the medium by an increase in $\mu_{\max }$ value and there are no notable differences at half saturation constants.

This study investigated free and immobilized Saccharomyces carlsbergensis growth kinetics and fermentation performance based on different kinetic models, Monod, Contois, Teisser and other models which present the substrate and product inhibition.

Entrapment and capsulation immobilization techniques are applicable, effective and of economic benefit. We recommend to use the entrapment immobilization technique because the beads are easier to obtain, more uniform, stable and smaller in size.

Immobilized yeast is easier to handle than the free cells. In addition, it could be reused both in batch and continuous processes. Gelatin immobilization techniques would be unrecommendable as cell growth is not supported. During fermentation, the diameter of immobilized beads increased and structure released more cells in the medium. Entrapment and capsulated immobilization techniques protected the morphology of cells, and supported cells growth and budding.

Microscopic surveys of immobilized yeast cells, shows notable differences in cell growth performance of gelatin immobilization technique compared to free and two other immobilization techniques. Budding, pseudomycelium formation, vitality and contamination was better in entrapment and capsulated immobilized yeast, compared to free cell suspension.

Even with slightly small differences, the entrapment immobilization technique is better compared to capsulation technique. This is due to the smaller, uniform and consistent breads, insuring a more stable fermentation process. This conclusion is sustained also referring to the kinetic constants.

Capsulation method in normal fermentation condition is less effective than entrapment and free yeast cell fermentation, but is more effective in inhibitory conditions. Impact of substrate and product inhibition decreased due to the immobilization techniques.

From the obtained results it is easy to choose a single best fitting model. Good approximation potential was shown by the models of Monod, Teisser, in non- 
inhibitory condition. Due to diffusion resistances fermentation performance is better with immobilized cells. Mathematical models both for substrate and product inhibition are exponential.

Entrapment and capsulation immobilization techniques are applicable, effective and of economic benefit. These techniques protected the morphology of cells, and supported cells growth and budding. In normal fermentation conditions entrapment immobilization is similar with free yeast cell fermentation. In inhibitory condition both immobilized methods are more effective than free yeast cell traditional fermentation. Better results gives capsulation immobilization method. This results are supported also by kinetic parameter investigation.

Kinetic parameters investigation of free and immobilized Saccharomyces carlsbergensis was done based on growth kinetics, ethanol productivity and substrate consumption (glucose) using computer simulation for different kinetic models, Monod, Contois, Teisser and other models which present the substrate and product inhibition.

Eleven of the most popular cultivation model structures were investigated. Good approximation potential was shown by the model of Monod, Teisser and Aiba. For substrate and product inhibition the most approximate models were exponential. Non-inhibitory fermentations fits with the Monod model, while product and substrate inhibition fermentation fits with exponential models.

\section{Acknowledgments}

We acknowledged Laboratory of "Stefani and Co" Brewery, Tirana Albania, providing industrial yeast strain, and for their assistance on our experimental and pilot batch experiments.

\section{References}

Aiba S et al., 2000, Shoda M, Nagatani M. Kinetic of product inhibition in alcohol fermentation. Biotechnology Bioengineering; pp. 67; 671-90. https://www.ncbi.nlm.nih.gov/pubmed/10699849.

Berlowska, J et al., 2013, Kregiel, D., Ambroziak, W. Physiological tests for yeast brewery cells immobilized on modified chamotte carrier. Antonie van Leeuwenhoek 104: pp. 703-714. https://link.springer.com/content/pdf/10.1007\%2Fs1 0482-013-9978-1.pdf
Biotechnology and Food Science, 75(1): pp. 65-86. http://yadda.icm.edu.pl/yadda/element/bwmeta1.ele ment.baztech-article-LOD7-0032-0048

Branik, T et al., 2005, Vicente, A.A., Dostalek, P. and Teixeira, J.A. Continuous Beer Fermentation Using Immobilized Yeast Cell Bioreactor Systems. American Chemical Society and American Institute of Chemical Engineering, 21: pp. 653-663. http://onlinelibrary.wiley.com/doi/10.1021/bp05001 $2 \mathrm{u} / \mathrm{abstract}$

Canaple, L. (2002). Improving cell encapsulation through size control. Journal of Biomaterials Science, Polymer Edition 13: pp 783-796.

Di Serio et al., 2001, M., Tesser, R. and Santacesaria, E. A kinetic and mass transfer model to simulate the growth of baker's yeast in industrial bioreactors. Chem. Eng. J. 82, 347-354. http://www.ingentaconnect.com/content/tandf/bsp/2 002/00000013/00000007/art00004

Duarte, J.C et al., 2013, Rodrigues, J.A.R., Moran, P.J.S., Valenca, G.P., Nunhez, J.R. Effect of immobilized cells in calcium alginate beads in alcoholic fermentation. AMB Express 3:31 https://link.springer.com/article/10.1186/2191-08553-31

Georgi Kostov et al., 2012, Modeling of Batch Alcohol Fermentation with Free and Immobilized Yeasts Saccharomyces Cerevisiae 46 EVD. Biotechnology \& Biotechnological Equipment, 26:3, 3021-3030

Gorecka, E. and Jastrzebska, M., 2011. Immobilization techniques and biopolymer carriers.

Kourkoutas,Y et.al., 2004, Bekatorou, A., Banat, I.M., Marchant, R., Koutinas, A. A. Immobilization technologies and support materials suitable in alcoholic beverages production. A review, Elsevier Food Microbiology 21: pp. 377-397. http://www.sciencedirect.com/science/article/pii/S0 740002003001072

Najafpour, G et al., 2004, Younesi, H. and Ismail, K.S.K. Ethanol fermentation in an immobilized cell reactor using Saccharomyces cerevisiae. Bioresource Technology, 92: pp. 251-260. https://www.academia.edu/10413842/Ethanol_ferm entation_in_an_immobilized_cell_reactor_using_Sa ccharomyces_cerevisiae

Olsson, L. and Nielsen, J., 2000. The role of metabolic engineering in the improvement of Saccharomyces cerevisiae: utilization of industrial media. Enzyme and Microbial Technology. 26, 785-792. http://www.sciencedirect.com/science/article/pii/S0 141022900001721 
Pilkington, P.H et al., 1998, Margaritis, A., Mensour, N.A., Russell, I. Fundamentals of immobilized yeast cells for continuous beer fermentation. A review. J. Inst. Brew. 104, pp 19-31. http://onlinelibrary.wiley.com/doi/10.1002/j.20500416.1998.tb00970.x/abstract

Rrathone, S et al., 2013, Desai, P.M., Liew, C.V., Chan, L.W., Heng, P.W.S. Microencapsulation of microbial cells. Journal of Food Engineering. 116(2):

pp.
http://www.sciencedirect.com/science/article/pii/S0 260877412006103

Snoep, J.L et al., 1999, Mendes, P., Westerhoff, H.V. Teaching metabolic control analysis and kinetic modeling towards a portable teaching module. The Biochemical Society.21, 25- 28. https://www.researchgate.net/publication/23781449 4_Teaching_Metabolic_Control_Analysis_and_kine tic_modelling_Towards_a_portable_teaching_modu le

\section{How to cite this article:}

Luljeta Pinguli, Ilirjan Malollari, Rozana Troja, Vilma Gurazi and Terkida Vaso. 2017. Impact of immobilization techniques of brewing strain Saccharomyces carlsbergensis on fermentation kinetics. Int.J.Curr.Res.Aca.Rev. 5(10), 42-52. doi: https://doi.org/10.20546/ijcrar.2017.510.007 